\title{
Mobile Applications for Developing Second Language Collaborative Writing
}

\author{
https://doi.org/10.3991/ijim.v15i07.19885
}

\author{
Sasi Sekhar Mallampalli ${ }^{(\bowtie)}$, Shriya Goyal \\ Uttaranchal University, Dehradun, India \\ mallampallisasisekhar@gmail.com
}

\begin{abstract}
Developing writing skills in a foreign language is one of the demanding tasks for both teachers and students. It not only demands extensive reading and intensive practice in writing both inside and outside the classroom but also timely feedback and error-correction. The experimental study aimed at studying the impact of collaborative writing tasks using mobile applications like WhatsApp, Google Docs, and Google Slides on enhancing the writing ability at the pre-intermediate level of Common European Frame of Reference (CEFR). The participants were tertiary level students of Cihan University who were randomly divided into two equal groups $(\mathrm{n}=28)$. One group used WhatsApp and the other group used the Google Docs and Google Slides apps on their mobile devices. The comparative study analyzed the impact of each application on improving the writing skills of the students with pretest and posttest results and semi-structured interviews. The results indicated that the participants who used Google Docs and Google Slides apps have performed better than the participants in the WhatsApp group. The results have implications for teachers teaching writing skills and students who write using mobile applications.
\end{abstract}

Keywords-Mobile Assisted Language Learning; Collaborative Writing; Mobile Apps for collaborative writing tools

\section{Introduction}

Writing effectively in a global language is not only one of the most challenging aspects of second language learning but also one of the most sought-after skills for employability and career success [1]. Communicating effectively using different technological tools is one of the essential skills in the digital age of communication. In order to prepare the students for the global workforce, it is imperative to train students in using different mobile applications individually and collaboratively.

\subsection{Importance of $\mathrm{L} 2$ writing skills using digital tools}

The 4Cs of 'Learning Skills' of 21st-century skills being Communication, Collaboration, Critical thinking, and Creativity - skills all learners need for success in college, workplace, and life [2]. Good writing skills for effective communication go a long way in keeping oneself ahead of others. The ability to communicate ideas and infor- 
mation effectively using digital tools is one of the most demanding skills for grabbing the best job opportunities.

\subsection{Mobile Assisted Language Learning (MALL)}

Mobile Assisted Language Learning (MALL) is one of the most widely recognized fields of mobile learning. It has attracted the attention of researchers and practitioners as one of the most promising fields of research for enabling millions of learners to learn and acquire skills in second language around the world. The user-friendly features and functions of mobile devices make them the most useful gadgets. The affordances of smartphones led educators and researchers to explore and experiment with the uses of these handheld devices in language pedagogy.

The availability of a good number of applications for learning a foreign or second language makes MALL the most convenient means of learning for millions of learners who can afford a smartphone. Learners can access rich learning materials anytime and from anywhere using the application that suits their learning needs. Affordability and accessibility are the two important factors that play a crucial role in choosing a mobile application.

\subsection{Affordances of MALL applications}

The affordances of each mobile application play a crucial role in choosing a particular mobile application for learning purposes. The availability of numerous applications that suit different learning styles and preferences of learners make MALL the most preferred means for language learning. Learners can access rich learning resources through their smartphones and enhance their English language skills with dictionaries, MP3s, podcasts, PDFs, YouTube, and social networking sites such as Facebook, Twitter among several language-learning apps.

\subsection{Informal learning through MALL}

Informal learning plays a crucial role in developing second language learning. Learners when they start interacting with others learn many things incidentally. Educators around the world are on the lookout for more innovative ways and seek to provide an interactive environment that engages students and motivates them to collaborate and share their ideas and experiences [3]. Online chatting applications offer immense scope for developing second language skills. Text messaging applications provide opportunities for developing writing skills in an informal learning setting.

Oxford [4] and Savignon [5] opine that communicative competence in a foreign/ second language could be developed through realistic interactions using meaningful and contextualized language. The limited-time that is allotted for the classroom is hardly enough for practicing language skills. Furthermore, classroom teaching is often driven by course books and provides little room for contextualized language use and interactions. Hence, it is highly imperative to create a space for students to practice and interact in the target language as much as possible to acquire a good level of communicative competence in the target language. 
The present study made an attempt to examine the efficacy and affordances of two mobile applications WhatsApp and Google Documents for developing writing skills collaboratively. The study was based on the proposition that students' writing skills in particular could be improved in an effective and engaging way through informal learning environments using the mobile applications.

\section{$2 \quad$ Related Literature}

Today's students can be aptly called "digital natives" as said by Prensky in [6] they are all 'native speakers' of the digital language of computers, video games, and the internet. In a sense, they are increasingly brought up with digital tools such as smartphones, tablets, and laptops as their learning is greatly influenced by these tools.

Miangah and Nezarat [7] have asserted that learners feel a greater sense of freedom of time and place so that they can take the advantage of spare time to learn a second language anytime and anywhere.

Fattah [8] carried out a study to determine the effectiveness of using a WhatsApp messenger to develop students' writing skills of Saudi private college students. The study recorded a significant improvement in the writing skills of participants. The study focused on improving writing skills by following a prescribed textbook.

Jafari and Chalak [9] studied the role of WhatsApp in teaching vocabulary to Iranian EFL junior school students. The study was limited to four weeks and it showed a remarkable improvement in improving their vocabulary. The results revealed that using WhatsApp in teaching vocabulary had a significant role in vocabulary learning. The results also showed that there was no substantial difference between male and female students with respect to their knowledge of vocabulary after using WhatsApp.

GencIlter [10] examined the effect of technology on motivation levels of students in EFL classrooms through questionnaires. The analysis proved that effective EFL activities could be facilitated by means of technology. Further, it revealed that EFL students welcome their teachers to bring in technology in their classrooms. It was noted that students found the classes more engaging by using the technology.

There are several studies which reported in a recent research paper, [11] stated that digital storytelling had a positive impact on the writing skills of the students. MALL had a positive impact on the improvement of the Indonesian pre-service teacher's writing skills from a critical thinking point of view as stated in [12]. The use of interactive mobile applications showed a significantly positive impact in improving the reading and writing skills of Spanish students at the primary level [13]. The use of social media and Wikis played an important role in enhancing the writing skills of students as evidenced in the review of 17 research papers [14]. Proficiency in English is considered one of the most essential skills for career success in Kurdistan [15].

As evident from the review of literature on the role of digital media in improving the writing skills of students, an experimental study was conducted to study the impact of two mobile applications in improving the writing skills of Kurdish students from Cihan University, Erbil. 


\section{$3 \quad$ Research Objectives}

The present study explores the efficacy, viability, and impact of WhatsApp and Google Docs, Google Slides applications for improving the pre-intermediate level (CEFR) writing skills of the tertiary level Kurdish students at Cihan University, Erbil. The study aims at studying the following research questions (RQ):

RQ1. Is there any difference in the writing performance between the two groups of participants who used WhatsApp and Google Docs and Google Slides separately?

RQ2. What are the perceptions of the participants about the affordances of the two mobile applications for enhancing the second language writing skills, as experienced by the participants?

\section{$4 \quad$ Methodology}

The study adopted both quantitative and qualitative methods in collecting and analyzing the data to obtain results and derive conclusions from the study. Participants were assigned into two groups randomly; the participants in group A $(n=28)$ used WhatsApp and the participants in group B $(\mathrm{n}=28)$ used Google Docs and Google Slides.

\subsection{Participants}

The participants in the study were the tertiary level students belonging to the second year of bachelor's degree in Translation Studies, at Cihan University, Erbil. The participants were at different levels of proficiency from A1 to B1 levels of Common European Frame of Reference (CEFR).

\subsection{Procedure}

The participants were taught writing skills for over a semester as a part of the prescribed curriculum in their course. The participants were assigned simple writing tasks at frequent intervals through the common Class WhatsApp group. However, group A used WhatsApp for completing the writing tasks and group B used Google Docs or Google Slides as indicated, created, and shared by the teacher with the participants. For both the groups, some of the tasks were synchronous and some were asynchronous. Pretest and post-tests were administered for both the groups for ascertaining the improvement in their performance.

\subsection{Materials/tools used}

- Common WhatsApp group for both the groups for communication and sharing and assigning writing tasks.

- A separate WhatsApp group for group A

- Google Docs and Google Slides apps for Group B 


\subsection{Writing tasks}

The following writing tasks were given to both groups at regular intervals throughout the semester.

1. Sentence formation with the given phrases

2. Short paragraph writing (25- 30 words)

3. Caption Writing

4. Summarizing the one-minute video lectures

5. Dialogue writing

6. Picture description

7. Completing the sentence stems/triggers

8. Cutting the deadwood (writing precisely)

9. Explain the given quote

10. Expressing opinion on a given topic

\subsection{Data collection}

Data was collected from the pretest and posttest for assessing the improvement in writing skills. Semi-structured interviews and face to face interactions were conducted with the participants of both groups.

\section{$5 \quad$ Results}

The results of the study are presented in the order of the research questions studied.

Research Question 1: Is there any difference in the writing performance between the two groups of participants who used WhatsApp (group A) and Google Docs and Google Slides (group B) separately?

In order to ascertain the difference in the performance of the two groups t-test was conducted and the scores were analyzed (as shown in Table 1).

Table 1. Descriptive Statistical Analysis

\begin{tabular}{|l|c|c|c|}
\hline & Sample size & mean & s.d \\
\hline Group-A & $\mathrm{n}_{\mathrm{a}}=28$ & $\mathrm{x}_{\mathrm{a}}=21.61$ & $\mathrm{~S}_{\mathrm{a}}=2.13$ \\
\hline Group-B & $\mathrm{n}_{\mathrm{b}}=28$ & $\mathrm{x}_{\mathrm{b}}=25.07$ & $\mathrm{~S}_{\mathrm{b}}=3.37$ \\
\hline
\end{tabular}

Note: considered the data Experimental group as A \& Controlled group as B

Sample sizes $n_{A}=28, n_{B}=28$

$$
\begin{aligned}
& \bar{X}_{A}=\frac{\sum x_{i}}{n_{A}}=21.61 \\
& \bar{X}_{B}=\frac{\sum x_{i}}{n_{B}}=25.07
\end{aligned}
$$




$$
S=\sqrt{\frac{\sum\left(x_{i}-\bar{x}\right)^{2}}{n-1}}
$$

a) N.H: $\mathrm{H}_{0}: \boldsymbol{\mu}_{\mathbf{B}}-\boldsymbol{\mu}_{\mathbf{A}}(=\delta)=\mathbf{0}$ (i.e., The performance is the same for both the groups $\mathrm{A}$ and $\mathrm{B}$.

b) A.H: $H_{1}: \boldsymbol{\mu}_{\mathbf{B}}-\boldsymbol{\mu}_{\mathbf{A}}>\mathbf{0}$ (i.e., The performance of Group B is better than that of the participants in group A.

c) L.O.S.: $\alpha=0.05$ (Right oriented Tailed Test) $\mathrm{t}_{0.005}=1.671$ with dof $v=\mathrm{n}_{1}+\mathrm{n}_{2}-2=$ 54

d) Critical Region: $\left|t_{\text {cal }}\right|>\left|t_{\alpha}\right|$ (reject Null Hypothesis)

e) Computation $\quad: \quad t_{c a l}=\frac{\left(\bar{x}_{B}-\bar{x}_{A}\right)-\delta}{\sqrt{\left(n_{B}-1\right) s_{B}^{2}+\left(n_{A}-1\right) s_{A}^{2}}} \sqrt{\frac{n_{A} n_{B}\left(n_{A}+n_{B}-2\right)}{n_{A}+n_{B}}}=$ $\frac{(25.07-21.61)-0}{\sqrt{(28-1) 2.13^{2}+(28-1) 3.37^{2}}} \sqrt{\frac{(28)(28)(28+28-2)}{(28+28)}}=4.59$

f) Decision: The null hypothesis was rejected as the calculated value is greater than the table value $|\mathrm{tcal}|>|\mathrm{t} \alpha|$

Hence, the performance of the participants in group B was better than the performance of the participants in group A.

Research Question 2. What are the differences and similarities between the affordances of the two mobile applications for enhancing the second language writing skills, as experienced by the participants?

Table 2. Affordances of WhatsApp and Google Document/ Slides

\begin{tabular}{|c|l|l|l|}
\hline S. No & \multicolumn{1}{|c|}{ Affordances } & \multicolumn{1}{|c|}{ WhatsApp } & \multicolumn{1}{|c|}{ Google Document/ Slides } \\
\hline 1 & Input through voice & Possible & Possible \\
\hline 2 & Auto-correction of spellings & Not possible & Possible \\
\hline 3 & Auto- Indication of errors & Not possible & Possible \\
\hline 4 & Identity of the student & $\begin{array}{l}\text { Visible during and after the } \\
\text { typing of the message }\end{array}$ & $\begin{array}{l}\text { Possible only during typing and } \\
\text { after that it is not possible }\end{array}$ \\
\hline 5 & Font and size selection & Not possible & Possible \\
\hline 6 & Number of maximum people & 256 & 100 \\
\hline 7 & Emojis and symbols & Possible & Possible \\
\hline 8 & $\begin{array}{l}\text { Collaborative composing of the } \\
\text { message }\end{array}$ & Not possible & Possible \\
\hline 9 & Sharing links & Possible and easy & $\begin{array}{l}\text { Possible but not as convenient as } \\
\text { it is in WhatsApp }\end{array}$ \\
\hline 10 & Identification of errors & Not possible & Possible \\
\hline 11 & Formal or informal mode & Informal & Formal \\
\hline 12 & Formatting of the text & Not possible & Possible \\
\hline 13 & Italics, bold, & Possible & Possible \\
\hline 14 & Underlining & Not possible & Possible \\
\hline 15 & Peer review & Possible & $\begin{array}{l}\text { Not possible to correct the } \\
\text { message, but can be sent as a } \\
\text { separate message }\end{array}$ \\
\hline 16 & Correcting others' mistakes & Possible & Possible to edit the message \\
\hline 17 & Tagging & Peply messages & Possible \\
\hline
\end{tabular}




\section{Discussion}

The experimental study brought out the differences and similarities in the affordances of the two mobile applications that were taken up for enhancing the writing skills of the participants.

The purpose of the two mobile applications is basically different, as WhatsApp is meant for instant messaging, and Google Docs and Google Slides are meant for creating documents collaboratively. However, for teaching the basic writing skills both the applications were used in the study in two separate groups. Keeping the simplicity of the tasks given in 4.4, both the applications were suitable.

As shown in Table 2, there are similarities and differences in the affordances of the two mobile applications. The similarities include voice input, Emojis, italics, bold letters, and replying to the previous messages. The differences are more than the similarities.

Among the differences in the mobile applications, the users reported ease in accessing the messages and sending the answers through WhatsApp. The identity of the sender of the message is clear in WhatsApp, whereas the identity of the writer is lost once the message was composed, though it is possible who is answering while the answers are being typed in both Google Docs and Google Slides.

Collaborative tasks were done with equal use in both applications. However, when all the 28 participants were working simultaneously, it was a clumsy experience in Google Docs, and participants reported extreme difficulty in keeping their paragraphs or sentences untouched by the other participants. The problem was overcome to some extent by using Google Slides by allocating each student a separate slide with a clear number on it. It is possible to erase or delete the work of other students in the Google Docs and Google Slides when they were shared with edit options. As the purpose of the study was to improve the writing skills of every participant, everyone in the same group was given edit access. However, the problem can be resolved only by giving a view option, but that was not possible for making corrections.

\section{Conclusion}

The study endorsed the previous research findings which reported a positive impact of mobile applications and the use of MALL in motivating, and engaging the learners actively and improving their writing skills informally even outside the classroom. The group that used WhatsApp felt they were learning in an informal way whereas the group that used Google Docs and Google Slides felt they were learning in a formal way though they were working outside the classroom. The participants expressed that they learnt their mistakes from the auto-correction/ suggestion feature in Google Docs whereas the WhatsApp participants double-checked their writing before they posted and learnt from the peer feedback more. 


\section{$8 \quad$ References}

[1] Ken Hyland (2003) Second Language Writing, Cambridge Language Education

[2] Bri Stauffer. (2020). What Are 21 st Century Skills? https://www.aeseducation.com/blog/ what-are-21st- century-skills

[3] Batianeh, A. M. (2014). The Effect of Text Chat Assisted with Word Processors on Saudi English Major Students' Writing Accuracy and Productivity of Authentic Texts. International Journal of Emerging Technologies in Learning (IJET), 9(9), 32. https://onlinejournals.org/index.php/i-jet/article/view/4119 https://doi.org/10.3991/ijet.v9i9.4119

[4] Oxford, R.L., 1991. Language learning strategies: What every teacher should know. Boston: Heinle.

[5] Savignon, S.J., 1997. Communicative competence: Theory and classroom practice. 2ndEdn., New York: McGraw-Hill.

[6] Prensky, M. (2001), "Digital Natives, Digital Immigrants Part 1", On the Horizon, Vol. 9 No. 5, pp. 1-6. https://doi.org/10.1108/10748120110424816

[7] Miangah, T.M. and A. Nezarat, (2012.) Mobile-assisted language learning. International Journal of Distributed and Parallel Systems, 3(1): 309-319. https://doi.org/10.5121/ijdps. 2012.3126

[8] Fattah, S.F.E.S.A., 2015. The effectiveness of using WhatsApp messenger as one of mobile learning techniques to develop students' writing skills. Journal of Education and Practice, 6(32): 115-127. https://files.eric.ed.gov/fulltext/EJ1083503.pdf

[9] Jafari, S. and A. Chalak, 2016. The role of WhatsApp in teaching vocabulary to Iranian EFL learners at junior high school. English Language Teaching, 9(8): 85-92. https://doi.org/10. 5539/elt.v9n8p85

[10] GencIlter, B. (2009). Effect of technology on motivation in EFL classrooms. Turkish Online Journal of Distance Education, 10(4), 136-158.

[11] Pei Rong Lim, \& Norah Md Noor. (2019). Digital Storytelling as a Creative Teaching Method in Promoting Secondary School Students' Writing Skills. International Journal of Interactive Mobile Technologies (IJIM), 13(07), 117-128. https://doi.org/10.3991/ijim.v13 i07.10798.

[12] Haerazi Haerazi, I Made Permadi Utama, \& Heri Hidayatullah. (2020). Mobile Applications to Improve English Writing Skills Viewed from Critical Thinking Ability for PreService Teachers. International Journal of Interactive Mobile Technologies (IJIM), 14(07), 58-72. https://doi.org/10.3991/ijim.v14i07.11900

[13] Hernández-Campos, E., Jaimez-González, C. R., \& Betzabet García-Mendoza. (2020). Interactive Mobile Applications to Support the Teaching of Reading and Writing of Spanish for Children in Primary Education. International Journal of Interactive Mobile Technologies (IJIM), 14(14), 64-79. https://doi.org/10.3991/ijim.v14i14.14925

[14] Mustafa Haidari, Rahmatullah Katawazai, \& Sanitah Mohd Yusof. (2020). The Use of Social Media and Wikis in Teaching Writing Skills: A Review Article. International Journal of Interactive Mobile Technologies (IJIM), 14(16), 168-179. https://doi.org/10.3991/ijim. v14i16.15531

[15] Sofi-Karim Mahdi (2015) English Language Teaching in the Kurdistan Region of Iraq 


\section{$9 \quad$ Authors}

Sasi Sekhar Mallampalli is pursuing research in English Language Teaching (ELT) at Uttaranchal University, Dehradun, India. After a two-year stint at Cihan University, Erbil, Kurdistan Iraq, he now resumed working at University of Petroleum and Energy Studies (UPES), Dehradun, India. He has participated and presented papers at national and international conferences. His research interests include Writing Skills at secondary and tertiary levels, Mobile Assisted Language Learning, Teaching with Technologies. mallampallisasisekhar@gmail.com

Dr. Shriya Goyal has more than 18 years of experience in teaching at Postgraduate and Undergraduate levels along with research experience. Many Research Scholars are pursuing their Ph.D. Research Work under her supervision. She has presented Research Papers and attended National and International Conferences, Seminars \& Workshops, and has many published articles in International Journals to her credit. dr_shriya19@yahoo.com

Article submitted 2020-11-17. Resubmitted 2021-01-26. Final acceptance 2021-01-28. Final version published as submitted by the authors. 